\title{
Attitudes, beliefs, and practices of providers and key opinion leaders on emergency contraception in India
}

\author{
M.E. Khan \\ Population Council \\ Deepthi S. Varma \\ Population Council \\ Isha Bhatnagar \\ Population Council \\ Anvita Dixit \\ Population Council \\ Martha Brady \\ Population Council
}

Follow this and additional works at: https://knowledgecommons.popcouncil.org/departments_sbsr-rh

Part of the Health Policy Commons, International Public Health Commons, Obstetrics and Gynecology Commons, Pharmacy and Pharmaceutical Sciences Commons, Public Health Education and Promotion Commons, and the Women's Health Commons

How does access to this work benefit you? Let us know!

\section{Recommended Citation}

Khan, M.E., Deepthi S. Varma, Isha Bhatnagar, Anvita Dixit, and Martha Brady. 2012. "Attitudes, beliefs, and practices of providers and key opinion leaders on emergency contraception in India." New Delhi: Population Council. 


\section{ATTITUDES, BELIEFS AND PRACTICES OF PROVIDERS AND KEY OPINION LEADERS ON EMERGENCY CONTRACEPTION IN INDIA}

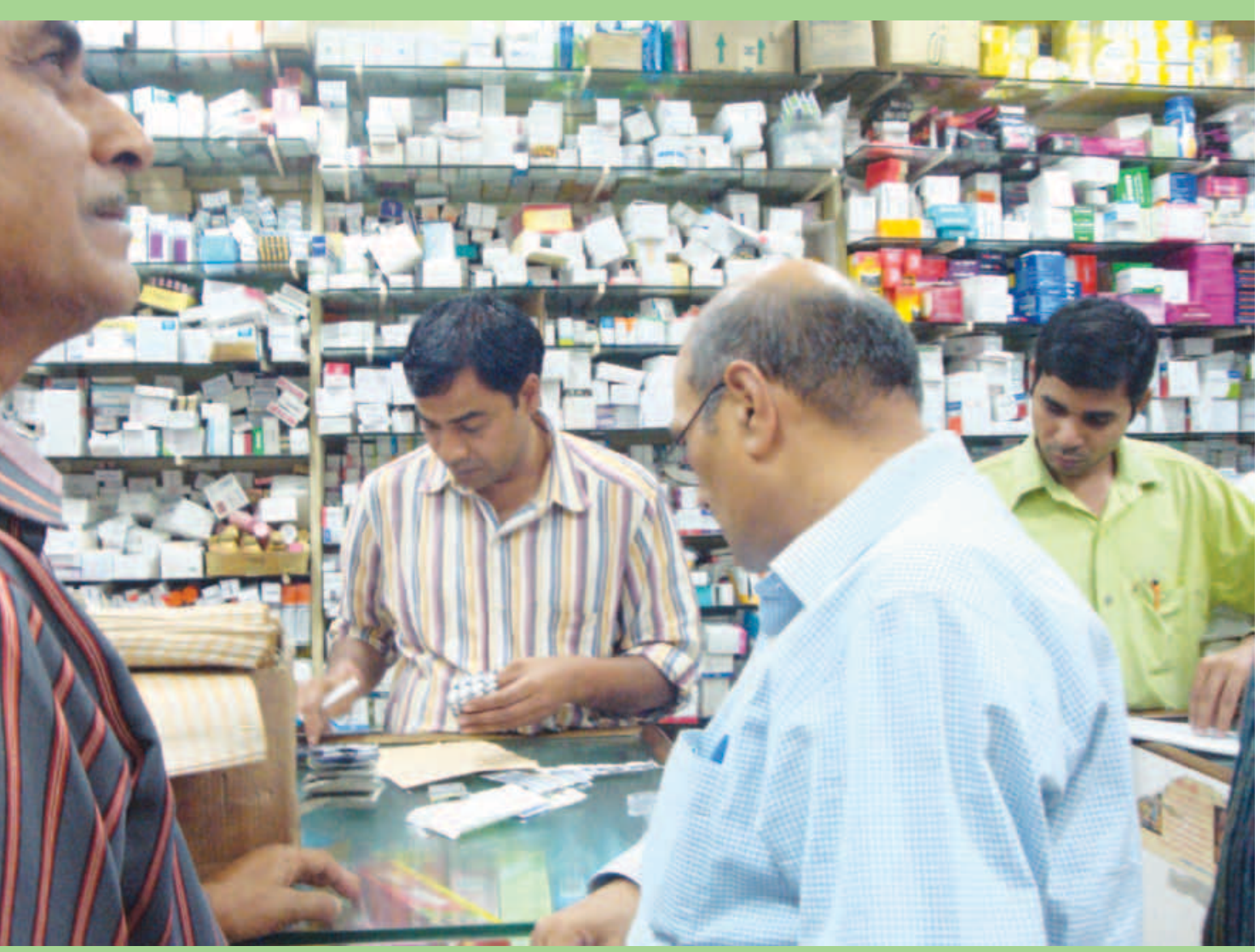

M.E. KHAN, DEEPTHI S. VARMA, ISHA BHATNAGAR, ANVITA DIXIT \& MARTHA BRADY

\section{(1) Population Council}




\title{
ATTITUDES, BELIEFS AND PRACTICES OF PROVIDERS AND KEY OPINION LEADERS ON EMERGENCY CONTRACEPTION IN INDIA
}

\author{
M.E. KHAN \\ DEEPTHI S. VARMA \\ ISHA BHATNAGAR \\ ANVITA DIXIT \\ MARTHA BRADY
}




\section{Population Council}

The Population Council confronts critical health and development issues-from stopping the spread of HIV to improving reproductive health and ensuring that young people lead full and productive lives. Through biomedical, social science, and public health research in 50 countries, we work with our partners to deliver solutions that lead to more effective policies, programs, and technologies that improve lives around the world. Established in 1952 and headquartered in New York, the Council is a nongovernmental, nonprofit organization governed by an international board of trustees.

Population Council

Zone 5A, Ground Floor

India Habitat Center

Lodi Road, New Delhi 110003

India

www.popcouncil.org

Copyright $@$ Population Council 2012

On the cover: A view of apharmacy shop in New Delhi.

Photo: Cover, pg ix \& pg x, courtesy of the Population Council.

Suggested Citation: Khan, M. E., Varma, D. S., Bhatnagar, I., Dixit, A., \& Brady, M. (2012). Attitudes, beliefs and practices of providers and key opinion leaders on emergency contraception in India. New Delhi: Population Council. 


\section{Table of Contents}

List of Abbreviations vi vi

Executive Summary vii

Introduction 1

Methodology 3

Key findings from the quantitative survey 4

Provider suggestions for increasing ECP knowledge 16

$\begin{array}{ll}\text { Findings from key opinion leaders } & 16\end{array}$

$\begin{array}{ll}\text { Attitudes towards repeated use } & 20\end{array}$

Supply, demand, and access $\quad 22$

Conclusions and recommendations $\quad 25$

$\begin{array}{ll}\text { References } & 28\end{array}$

$\begin{array}{ll}\text { Appendix } & 31\end{array}$ 


\section{List of Tables}

Table 1: $\quad$ Sample size of quantitative study 3

Table 2: $\quad$ Area of expertise of key informants 4

Table 3: $\quad$ Providers' socio-demographic characteristics 4

Table 4: $\quad$ Percent of providers trained on FP and ECP 5

Table 5: Providers' knowledge of ECP's mechanism of action 6

Table 6: $\quad$ Providers' opinions on who can use ECP 7

Table 7: $\quad$ Providers' opinions on circumstances when ECP is appropriate

Table 8: $\quad$ Providers' view on minimum age of ECP 8

Table 9: $\quad$ Providers' view of minimum age for ECP use 8

Table 10: Providers' opinions of ECP's safety and effectiveness 9

Table 11: Knowledge of ineligibility criteria (ECP use) 9

Table 12: Provider attitudes and beliefs about ECP access and availability

Table 13: Impressions of providers who use ECP

Table 14: Attitudes of providers towards ECP user's sexual behavior

Table 15: Percentage of women buying ECP more than once

Table 16: Service and information provided to customers requesting $\mathrm{ECP}$

Table 17: Definition of repeated ECP use, reported by key opinion leaders 


\section{List of Figures and Boxes}

Figure 1: Providers' knowledge of ECP's mechanism 6

Figure 2: $\quad$ Providers opinions on repeated use within one menstrual cycle $\quad 14$

Figure 3: $\quad$ Types of ECP dispensed by providers 15

Box: $\quad$ Key recommendations for increasing ECP access 24 


\section{List of Abbreviations}

\begin{tabular}{ll} 
ANM & Auxiliary Nurse Midwife \\
ASHA & Accredited Social Health Activist \\
AWW & Anganwadi Worker \\
BMGF & Bill and Melinda Gates Foundation \\
CHW & Community Health Worker \\
ECP & Emergency Contraceptive Pill \\
FIGO & International Federation of Gynecology and Obstetrics \\
FP & Family Planning \\
HIV & Human Immunodeficiency Virus \\
ICEC & International Consortium for Emergency Contraception \\
IDI & In Depth Interview \\
IIPS & International Institute for Population Sciences \\
KOL & Key Opinion Leader \\
MoHFW & Ministry of Health and Family Welfare \\
NGO & Non Governmental Organization \\
OR & Odds Ratio \\
OTC & Over the Counter \\
STI & Sexually Transmissible Infection \\
UHI & Urban Health Initiative \\
UP & Uttar Pradesh \\
WHO & World Health Organization \\
& \\
\hline
\end{tabular}




\section{Executive Summary}

\section{Background}

The emergency contraception pill (ECP) is an important method of contraception which can be used after sex to prevent unintended pregnancy in case a method is not used or has failed. Considering the high rate of unwanted pregnancy in India, the ECP was introduced in the National Family Planning Program in 2002 and made Over the Counter (OTC) drug in 2005. Evidence shows a very low knowledge and use of ECP. Providers' attitudes and lack of media coverage appear to be barriers to access and use of ECP. Moreover, ever since ECP has been made available as an OTC, there have been concerns that it may be misused leading to repeated use, increase in premarital sex and promiscuity, replacement of other regular family planning methods.

\section{Objectives}

The Population Council undertook this study to assess the knowledge, attitudes, and practices regarding ECP among providers in public and private facilities and pharmacies. The objectives of the study were to:

- Assess providers' knowledge of ECP's biological mechanism;

- Understand providers' knowledge and attitudes about ECP's safety, effectiveness, and availability as an OTC drug;

- Identify providers' definitions of 'repeated use' and profiling women who are 'repeated users' of ECP.

\section{Methodology}

A quantitative survey was conducted in four cities of Uttar Pradesh (Agra, Lucknow, Kanpur and Aligarh) and Delhi covering 315 providers (199 pharmacists, 83 gynecologists and 33 paramedics). The qualitative interviews of 19 experts (eight gynecologists, seven government officials at MoHFW, three development organization officials and one ECP manufacturing firm professional) referred to as key opinion leaders were carried out.

\section{Key findings}

- Doctors (96 percent) knew that the mechanism of ECP prevents pregnancy (prevents implantation) whereas many paramedics (40 percent) and most pharmacists (61 percent) lacked this knowledge. Eighty Four percent providers believed that ECP is a safe and effective method.

- There were some misconceptions such as; ECP cannot be used by women with heart problems or while breastfeeding, ECP can have serious side effects. 
- Many providers also showed negative attitudes which act as a barrier towards accessibility of ECP. More doctors than other providers disapprove ECP as OTC drug. Most favored minimum age restriction to provide ECP and believed ECP will promote promiscuity. Doctors held stronger negative attitudes towards ECP use and ECP provision by CHWs and ANMs.

- Favourable attitude was found among those who were trained in ECP or had read literature on ECP. A logistic regression showed that younger, trained and male providers were more likely to support ECP provision in comparison to older, untrained and female providers.

- $\quad$ Repeat use came up as an important issue related to OTC availability of ECP. There was confusion among KOLs and providers on what counts as repeated use. Most providers said that ECP used 2-3 times within same cycle is considered repeated use and discouraged repeated use. Sixty to 75 percent believed that ECP is being used repeatedly.

\section{Way forward}

This study's findings revealed many biases and gaps in knowledge, lack of training, moral reservations and misuse. These can be used to develop programs to increase knowledge and access to ECP. An advocacy strategy including an educational campaign is needed to tackle the negative attitudes of doctors and other stakeholders.

The Government should remove the current ban on ECP advertising but provide guidelines to manufacturers for their advertisements so that careful advertisements which promote ECP to be used in emergency only can be broadcasted. In all advertisements of condoms and pills, ECP should be added as a backup support. Companies who advertise their ECP brand on TV and newspapers should also mention that it is not a regular contraceptive method. 


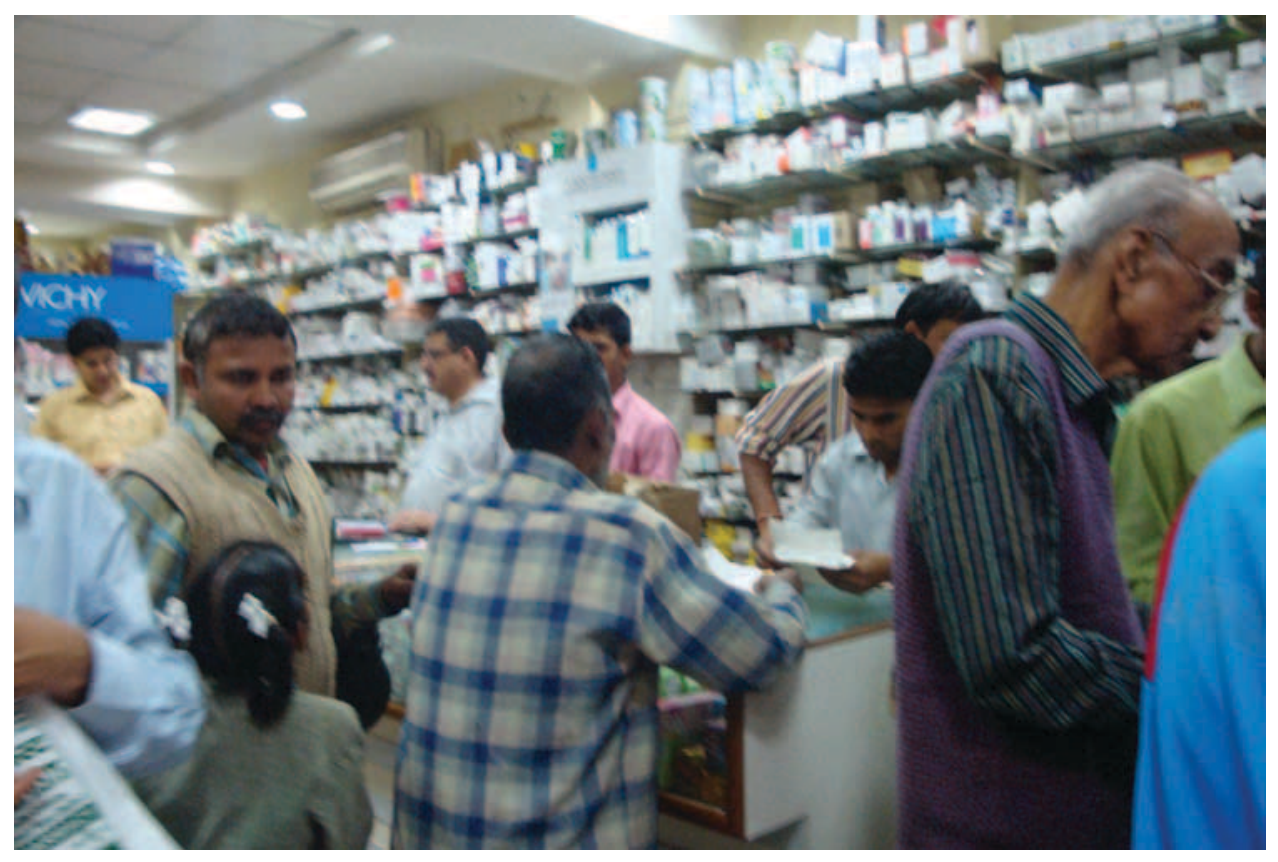

A pharmacy crowded by customers in New Delhi

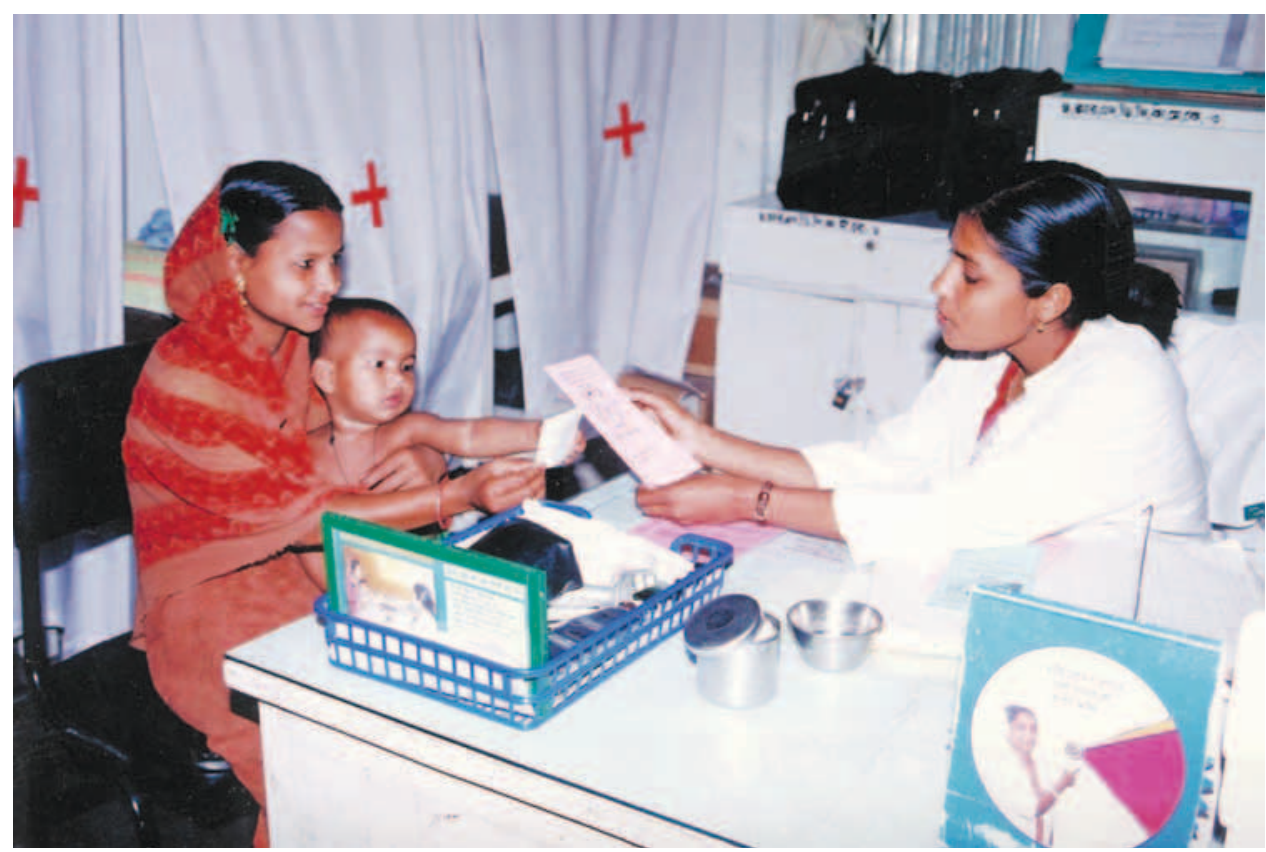

Nurse in a post-partum center talking with client about family planning methods 


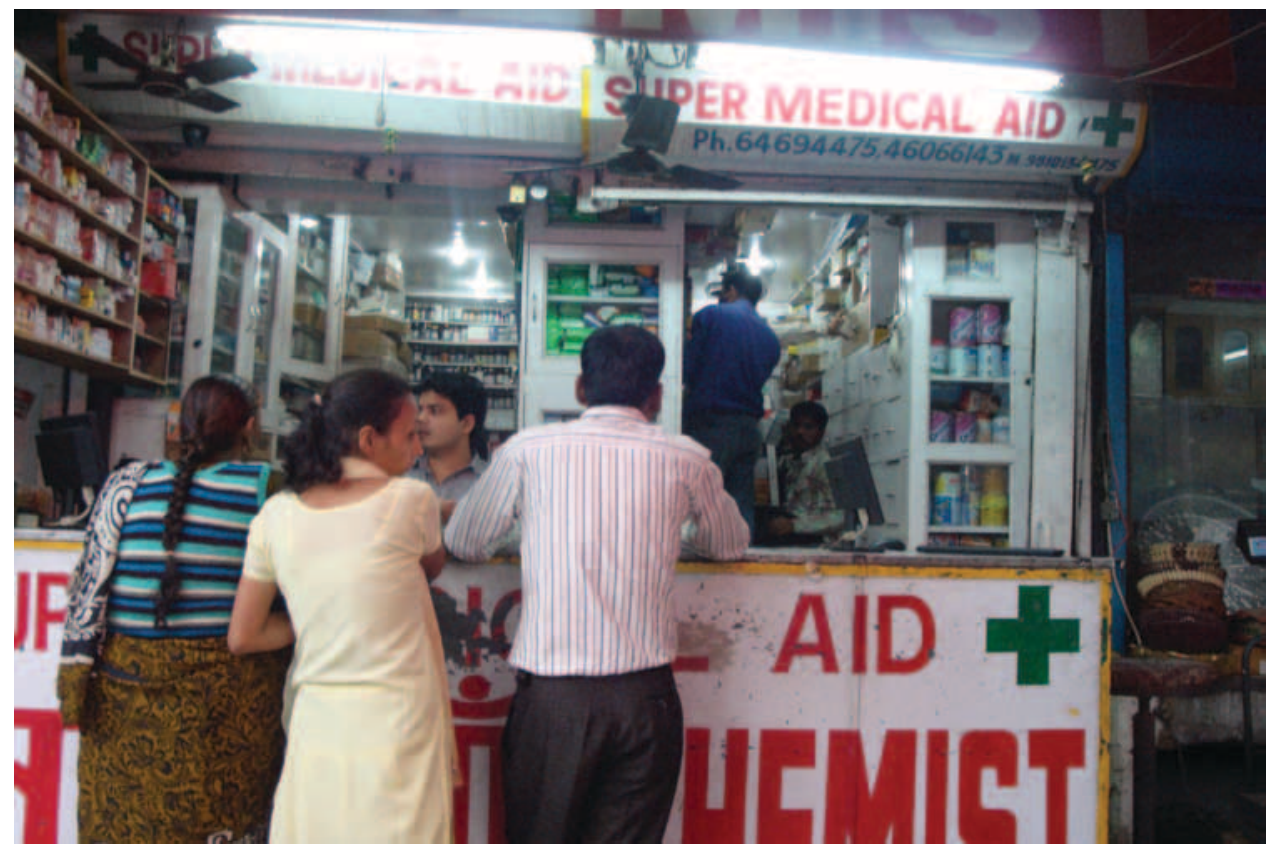

A chemist shop located near one of the largest hospitals in New Delhi

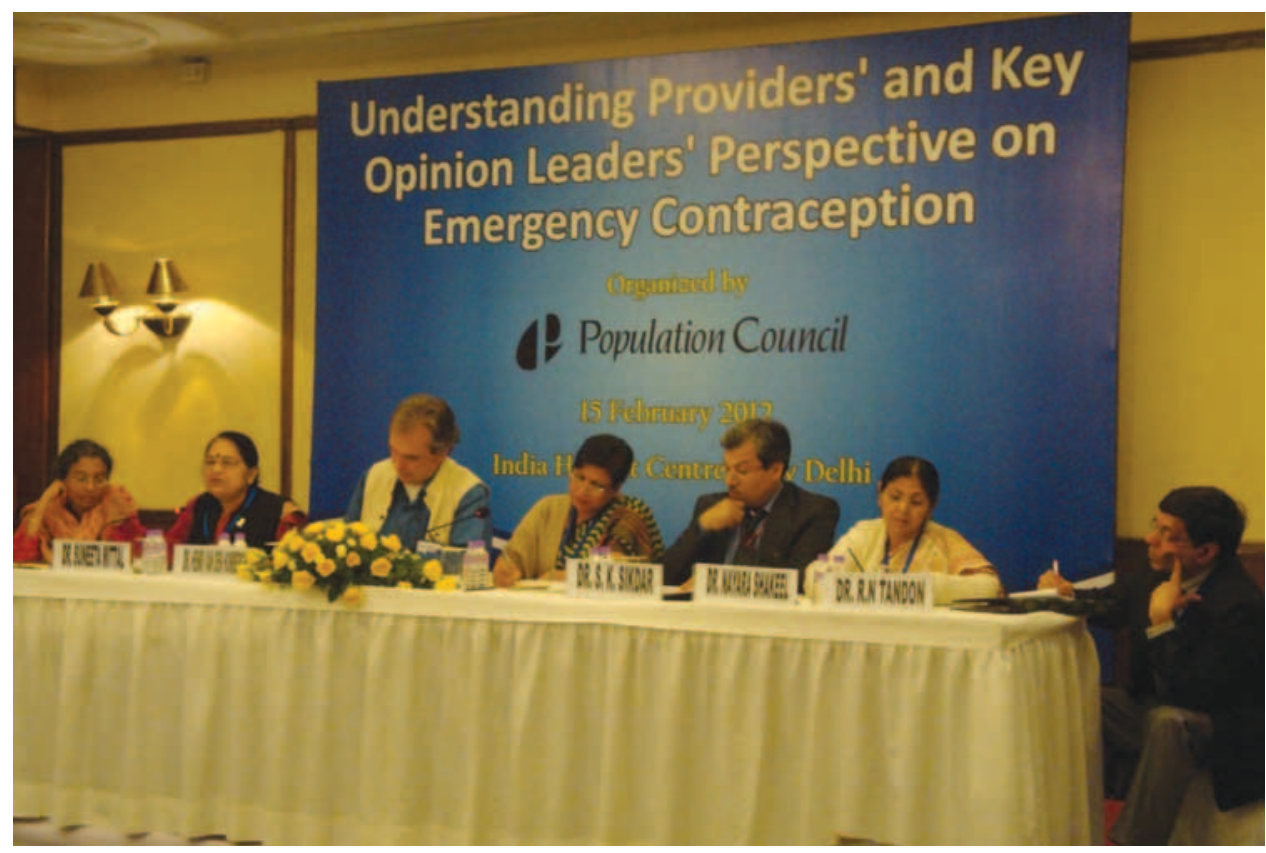

Panelists from the public sector and medical associations at a consultation meeting in New Delhi 


\section{Introduction}

The Emergency Contraception Pill (ECP) is a hormone-based method providing a woman with an opportunity for preventing unwanted pregnancy after intercourse (Camp, Wilkerson \& Raine, 2003; Croxatto et al., 2004; Hossain-Sharif, Khan, Sebastian \& Roychowdhury, 2008). ECP is an important component of the range of contraceptive services in India, where unmet family planning (FP) need is about 21.3 percent (IIPS, 2010). Several research studies across the globe have shown that ECP is safe, convenient to use, and can be effective in preventing unwanted pregnancies (WHO \& JHUCCP 2011). Findings from these research studies have encouraged several countries, including India, to make ECP available "over the counter" (OTC), without prescription.

In India, ECP was approved and introduced into the National Family Planning Program in 2002, and made an OTC drug in 2005. As an OTC drug, ECP can also be stocked and distributed by paramedics and community health workers (CHWs). Subsequently, it has been made available by government as well as non- governmental organizations along with existing contraceptives and promoted as a product that could be given in case of emergency. Data from the District Level Household and Facility Survey (IIPS, 2010) show that less than 1 percent $(0.5$ percent of rural and 0.8 percent of urban) of married women have ever used ECP. Furthermore, less than one-third of surveyed unmarried women knew about ECP. Awareness among currently married rural women was much lower, at 24 percent, compared to urban women at 47 percent (IIPS, 2010). Another study during the same period (Puri et al., 2007) among female college students from Chandigarh in northern India reported only 7.3 percent of 1,017 students knowing that ECP exists. A more recent study in a medical college among a smaller sample of 300 students largely from the rural population of Uttar Pradesh (UP) showed even lower (2 percent) knowledge (Nigam, Maheshwari \& Prakash, 2010). A recent study by Population Council in rural Bihar found that 5 percent women were aware of ECP, and less than 1 percent had ever used it (Bhatnagar \& Khan, 2011).

Several individual, community and system barriers contribute to limited ECP awareness and use, including lack of accurate knowledge of its mechanism and providers' religious affiliations and fear that wide ECP availability may lead to increased sexual partners or early initiation of sex (Aksu, Basak, Yeniceri \& Kaya, 2011; Rubin, Grumet \& Prine, 2006; Sychareun, Phongsavan, Hansana \& Phengsavanh, 2010). Further studies have shown that providers believe easy access to ECP may lead women not only to be less likely to use other more reliable methods, but to initiate sex at a younger age, have more sexual partners, encourage sexual risk-taking, increase their risk of acquiring HIV and other STIs as well (Lawrence, Rainski, Yoon \& Curlin 2010; Ehrale \& Sarker, 2011; Yam et al., 2007; Blanchard, Harrison \& Sello, 2005). Moreover, 
providers in general tend to overestimate ECP's contraindications and side effects and do not completely support its provision without prescription (Aksu et al., 2011; Ehrle \& Sarker, 2011) A study in UP has revealed that CHWs have incorrect and poor knowledge about safe methods (Goel, Bhatnagar, Khan \& Hazra, 2010).

Although limited in number, India studies show a lack of awareness among providers about correct prescribed doses of ECP and prescribed time of use (Kishore \& Misro, 2010; Goel et al., 2010; Bhatnagar \& Khan, 2011). Similar to reports from other countries, providers in India also believe ECP is an essential component of contraceptive services but prefer it to be distributed only through health care providers (Tripathi, Rathore \& Sachdeva, 2003; Kishore \& Misro, 2010; Kumar et al., 2007). The fear that easy ECP access will increase promiscuity and misuse is found among all providers in India (Kishore \& Misro, 2010). Another study finds that not only is ECP awareness low among CHWs such as Accredited Social Health Activists (ASHAs) (15 percent) but only 3.3 percent had ever been supplied with ECPs (Bhatnagar \& Khan, 2011).

Absence of uniform guidelines defining 'repeated use' and the number of times ECP can be used safely within the same menstrual cycle also creates hesitation about its provision among providers. Although the World Health Organization (WHO) (WHO Factsheet 244, 2005) has clearly stated that repeated ECP use does not pose any serious health risks other than minor menstrual disturbances, most providers continue to be apprehensive about repeated ECP use. These fears and hesitations are further fuelled by negative media coverage creating an imbalanced view of side-effects as well as widespread misuse, especially by unmarried young girls. For example, a recent Times of India article (July $23^{\text {rd }}$ 2011, Delhi edition, Appendix), "Morning- after-pill: a medical nightmare?" portrays ECP use by young women in Delhi along with strong opinions against ECP by several well-known medical practitioners in the city. The article concludes with the warning "think twice before you pop the pill," creating ambiguity among the readers, and such media coverage may discourage greater use and engender unfavorable attitudes towards ECP, not only among potential users but among providers and policy makers as well.

The Population Council undertook this study to assess the knowledge, attitudes, and practices regarding ECP among providers in public and private facilities and pharmacies. This study's objectives are:

- Assessing providers' knowledge of ECP's biological mechanism;

- Understanding providers' knowledge and attitudes about ECP's safety, effectiveness, and availability as an OTC drug; 
- Identifying providers' definitions of 'repeated use' and profiling women who are 'repeated users' of ECP.

This study's findings can be used to develop intervention programs and advocacy strategies increasing knowledge and access to ECP.

\section{Methodology}

\section{Quantitative survey of ECP providers}

The quantitative survey was conducted in three of the four UP cities which were part of the Urban Health Initiative (UHI) project funded by the Bill and Melinda Gates Foundation (BMGF), as well as in Delhi, the largest city in India, with a high volume of ECP sales. The study was initially planned in the four UP UHI cities (Lucknow, Aligarh, Agra and Kanpur), but initial investigation and a consultative workshop indicated that Delhi has India's largest volume of ECP sales, and so Delhi replaced Kanpur. Subsequent surveys in the three UP cities revealed that pharmacy shops are the single most important source of ECP supply, followed by some Family Welfare Centers, and qualified doctors are consulted primarily in case of problems (e.g. menstrual issues or ECP failure), so consequently only pharmacy shops were sampled in Delhi.

Lucknow, Aligarh, and Agra are of varying sizes, with populations of diverse backgrounds and characteristics. UHI has developed an exhaustive list of public health sector facilities, maternity and nursing homes as well as a complete list of different types of providers and health workers in each city. UHI's lists served as a sampling frame for the study, but in the absence of a similar systematic listing for Delhi, a sampling frame was developed from a census of all pharmacy shops in selected areas of Delhi.

Each city was divided into four zones—east, west, north, south—and UHI's list for that city was used to locate providers in each zone. The sample was purposively selected so that providers were near or in large residential areas, urban slums, or large institutions. A total of 315 providers were selected on the criterion of ever having provided ECP services and were interviewed October and November 2011 (Table 1).

Table 1: Sample size of quantitative study

\begin{tabular}{lcccccc} 
Type of & Agra & Lucknow & Aligarh & Kanpur & Delhi & Total Sample \\
\hline Qualified doctors & 42 & 20 & 19 & 2 & 0 & 83 \\
Pharmacists & 38 & 55 & 41 & 8 & 57 & 199 \\
Other providers & 6 & 20 & 6 & 1 & 0 & 33 \\
\hline Total & 86 & 95 & 66 & 11 & 57 & 315
\end{tabular}




\section{Qualitative survey of key opinion leaders}

The qualitative survey added another dimension to its examination of ECP in India by including in-depth interviews (IDIs) with key opinion leaders (KOLs) including leading $\mathrm{Ob} / \mathrm{Gyn}$ experts, senior officials of medical associations (such as the Indian Medical Association and Federation of Obstetric Gynecological Societies of India), senior officials of donor agencies, and senior program managers of the Ministry of Health and Family Welfare of the UP and federal governments. All KOLs were considered to be influential both in shaping health and FP policies and implementing family welfare programs or providing resources for programs and

Table 2: Area of expertise of key informants

\begin{tabular}{lc} 
Area of expertise & Number \\
Medical fraternity $^{1}$ & 8 \\
Government officials $^{\text {Development organizations }}$ & 7 \\
Manufacturing organization & 3 \\
\hline Total & 19 \\
\hline
\end{tabular}
research. Altogether, 19 KOLs were purposively selected (Table 2).

\section{Key findings from the quantitative survey}

\section{Providers' socio-demographic characteristics}

Among 315 providers surveyed, 63 percent were pharmacists, 26 percent were qualified doctors, and 10 percent were providers such as Auxiliary Nurse Midwives (ANMs),

Table 3: Providers' socio-demographic characteristics (percent)

\begin{tabular}{lcccc}
\hline Age/gender \& qualification & Qualified doctors & Other providers & Pharmacists & Total \\
\hline$<25$ years & 1.2 & 0.0 & 15.6 & 10.2 \\
25-34 years & 9.6 & 24.5 & 15.6 & 24.8 \\
35-44 years & 48.2 & 24.2 & 29.1 & 33.7 \\
$>=45$ years & 41.0 & 51.5 & 24.1 & 31.4 \\
Median age (years) & 42 & 45 & 35 & 39 \\
\hline Male & 2.4 & 30.3 & 97.0 & 65.1 \\
Female & 97.6 & 69.7 & 3.0 & 34.9 \\
\hline Doctor (Ob/Gyn) & 75.9 & 0.0 & 0.0 & 20.0 \\
Doctor (Others) & 23.1 & 0.0 & 0.0 & 6.3 \\
Pharmacist & 0.0 & 0.0 & 14.1 & 8.9 \\
Registered Nurse/Social Worker & 0.0 & 48.5 & 3.0 & 7.0 \\
Learnt by Practice & 0.0 & 51.5 & 82.9 & 57.8 \\
\hline Total (N) & 83 & 33 & 199 & 315
\end{tabular}

${ }^{1}$ Medical fraternity includes members of key medical organizations and gynecologists. The list may or may not overlap. 
staff of social marketing agencies, and counselors in FP clinics attached to large public facilities. Two-thirds of providers were male and one-third female, due primarily to the fact pharmacists were principally surveyed, most pharmacists were males. Pharmacists were also, on average, seven to 10 years younger than doctors and other providers (Table 3).

\section{Training on ECP}

Among the 315 providers in this study, out of which 19 percent had started working before 1990, 32 percent between 1991 to 2000 and 50 percent after 2000, one-third had been trained in FP in general and only 21 percent had been specifically trained in providing ECP. A relatively larger proportion of doctors, compared to other providers or pharmacists, had been trained in ECP, and more than half were trained after 2007 (Table 4).

Table 4: Percent of providers trained on FP and ECP

\begin{tabular}{lcccc} 
& Qualified doctors & Other providers & Pharmacists & Total \\
\hline Ever received training in FP & 67.5 & 63.6 & 12.1 & 32.1 \\
Ever received training in ECP & 43.4 & 24.2 & 10.6 & 20.6 \\
Received brochures or any & & & & \\
reading materials on ECP & 10.8 & 15.2 & 14.2 & 13.4 \\
\hline Total $(\mathrm{N})$ & 83 & 33 & 199 & 315 \\
\hline
\end{tabular}

Only 13 percent of providers reported receiving any brochures or other reading materials on ECP at any time, yet all of these providers reported having read the materials. The sources of these materials were mostly medical representatives, with some providers receiving them from NGOs, social marketing agencies, and the Ministry of Health and Family Welfare.

Twenty nine percent providers (23 percent doctors, 52 percent paramedics and 28 percent pharmacists) expressed the need for brochures to provide information on ECP to their clients whereas 71 percent providers did not feel such need as 82 percent believed they had sufficient knowledge to provide ECP.

\section{Knowledge of ECP mechanism}

Almost half of providers believed that ECP prevents implantation, while 12 percent felt ECP inhibits ovulation. A large proportion reported not knowing how ECP prevents pregnancy (Table 5). The latest literature on ECP states that it does not prevent implantation in any way (FIGO \& ICEC, 2012), and thus this belief, largely held by doctors, needs to be addressed and corrected. 
Qualified doctors were relatively more knowledgeable among providers interviewed, probably because more of them have received technical education on ECP, whereas pharmacists were the least knowledgeable. It is important to note that 61 percent of pharmacists did not know how ECP works. Almost all providers (96 percent), however, mentioned that ECP needs to be taken within 72 hours of unprotected sexual intercourse, largely because of the guidelines for administration by
Table 5: Providers' knowledge of ECP's mechanism of action (percent)*

\begin{tabular}{|lc|} 
Mechanisms of action & Total \\
\hline Inhibits ovulation & 12.1 \\
Prevents Implantation & 46.3 \\
Induces abortion & 3.5 \\
Kills sperm & 0.3 \\
Do not know & 42.5 \\
\hline Total $(N)$ & 315 \\
\hline
\end{tabular}

*Percentages may not add to 100 because of multiple responses

healthcare providers of ECPs issued by India's Ministry of Health and Family Welfare, which states "emergency contraceptive pills must be preferably taken within 72 hours of an unprotected act of intercourse, the earlier the better" (MoHFW, 2008). However, WHO's guidelines state that ECP can be taken within 120 hours. Following MoHFW guidelines, national advertising (when permitted) also endorsed ECP use within 72 hours rather than 120 hours.

Figure 1: Providers' knowledge of ECP's mechanism (percent)

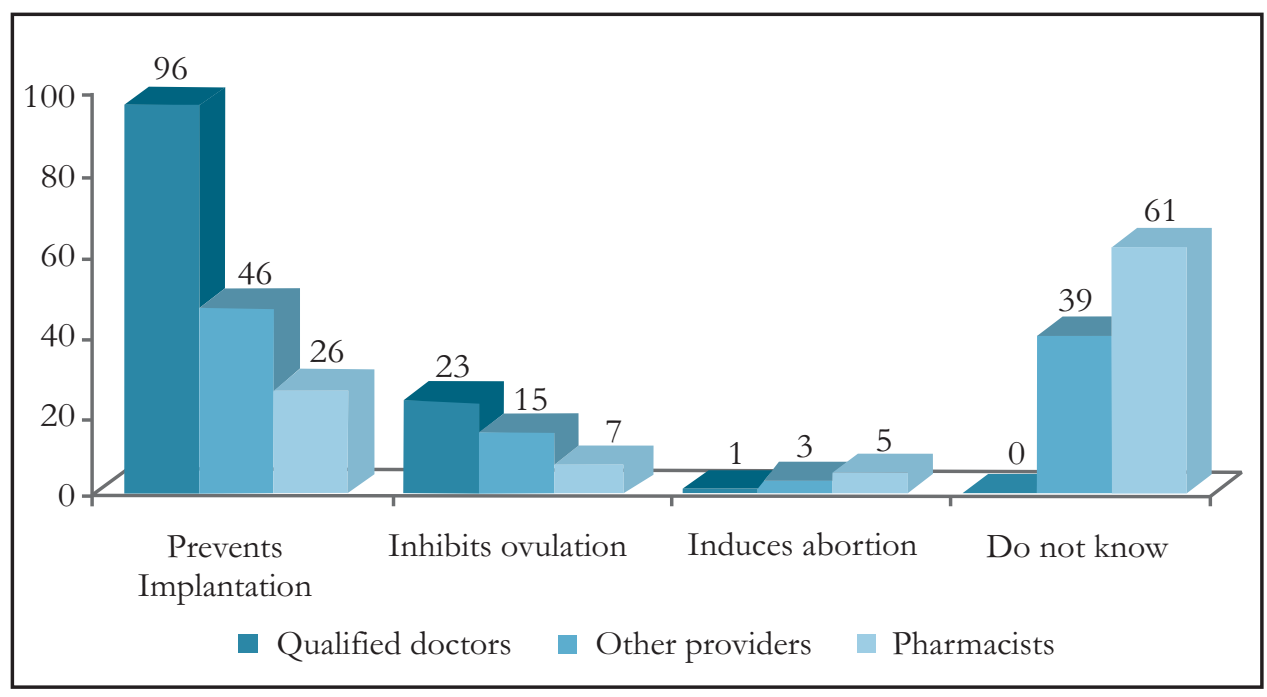

A question on whether providers thought ECP is an abortifacient revealed that twothirds knew ECP is not an abortifacient, while 16 percent thought it is; 18 percent were unsure. Variations according to provider type were discernible; 90 percent of qualified doctors and 72 percent of other providers said ECP is not an abortifacient, while only 
55 percent of pharmacists knew it is not. Conversely, more pharmacists (20 percent) than other providers (12 percent) and qualified doctors (10 percent) believed it is an abortifacient, with one quarter of pharmacists unsure.

\section{Women eligible for ECP}

Table 6: Providers' opinions on who can use ECP (percent)*

\begin{tabular}{lcccc} 
Type of women & Qualified doctors & Other providers & Pharmacists & Total \\
\hline $\begin{array}{l}\text { Married women } \\
\text { Adolescent/ }\end{array}$ & 78.3 & 90.9 & 79.4 & 80.3 \\
unmarried women & 60.2 & 39.4 & 61.8 & 59.0 \\
Rape survivors & 20.5 & 6.1 & 3.0 & 7.9 \\
Any women & 24.1 & 12.1 & 17.1 & 18.4 \\
Others & 0.0 & 0.0 & 1.0 & 0.6 \\
Do not know & 0.0 & 0.0 & 1.5 & 1.0 \\
\hline Total (N) & 83 & 33 & 199 & 315
\end{tabular}

*Percentage adds to more than 100 because of multiple replies

Only 18 percent of providers mentioned that any woman is eligible to use ECP. Although more than half (59 percent) of providers said adolescent or unmarried women could use ECP, a large majority ( 80 percent) felt married women are most eligible for using ECP (Table 6).

\section{Table 7: Providers' opinions on circumstances when ECP is appropriate (percent)}

\begin{tabular}{lcccc} 
Circumstances & Qualified doctors & Other providers & Pharmacists & Total \\
Rape or sexual & 26.5 & 9.1 & 11.6 & 15.2 \\
Infrequent/unpredicted sex & 61.4 & 60.6 & 51.8 & 55.2 \\
Engaged in sex work & 7.2 & 3.0 & 9.0 & 7.9 \\
Unprotected sex & 41 & 27.3 & 15.1 & 23.2 \\
Living as refugee/in conflict & 7.2 & 6.1 & 1.0 & 3.2 \\
Contraceptive failure & 12 & 12.1 & 6.5 & 8.6 \\
Others & 2.4 & 0.0 & 1.5 & 1.6 \\
Do not know & 0.0 & 0.0 & 0.5 & 0.3 \\
\hline Total (N) & 83 & 33 & 199 & 315
\end{tabular}


Further questioning on the circumstances when ECP is appropriate shows that providers accept a number of situations in which ECP could be useful and appropriate (Table 7).

When asked whether there should be a minimum age for ECP provision, most providers (73 to 94 percent) favored minimum age restriction for ECP (Table 8).

Table 8: Providers' view on minimum age for ECP (percent)

$\begin{array}{lccccc} & & \text { Qualified doctors } & \text { Other providers } & & \\ & & & & & \\ \text { Should there be } & \text { Yes } & 84.3 & 93.9 & 73.5 & 78.5 \\ \begin{array}{l}\text { a minimum age } \\ \text { restriction }\end{array} & \text { No } & 12.0 & 3.0 & 17.0 & 14.2 \\ \text { for ECP? } & \text { Cannot say } & 3.6 & 3.0 & 9.5 & 7.3 \\ & \text { Total (N) } & 83 & 33 & 199 & 315\end{array}$

When asked further on what age should be considered minimum, answers ranged from 14 to 45 years. (Table 9) Only approximately 14 percent of providers overall, more so among pharmacists (17 percent), felt no need for age restrictions.

Table 9: Providers' view of minimum age for ECP use (percent)*

\begin{tabular}{lcccc} 
Minimum age for ECP & Qualified doctors & Other providers & Pharmacists & Total \\
\hline 14 - 18 years & 27.1 & 29.0 & 49.0 & 40.5 \\
19 - 24 years & 28.6 & 41.9 & 35.4 & 39.3 \\
$>=25$ years & 24.3 & 29.0 & 15.0 & 19.8 \\
\hline Total $(\mathrm{N})$ & 70 & 31 & 147 & 247
\end{tabular}

*Based on responded who favored age restriction for providing ECP

Over 40 percent of respondents mentioned the ages of 14 to 18 as minimum age for ECP provision, while an almost equal proportion (39 percent) recommended 19 to 24 years; around 16 percent suggested the age of 25 . Disintegrated data show that the majority (32 percent) of providers believed the age of 18 should be the minimum for providing ECP; interestingly, 18 is also the minimal legal age of marriage for girls. Another one-fifth recommended 20 years as the minimum age for providing ECP. 


\section{Safety and effectiveness of ECP and contraindication knowledge}

The vast majority of providers believed ECP is safe and effective in preventing pregnancy (Table 10):

Table 10: Providers' opinions of ECP's safety and effectiveness (percent)

\begin{tabular}{lcccc}
$\begin{array}{l}\text { Opinion } \\
\text { Safety }\end{array}$ & Qualified doctors & Other providers & Pharmacists & Total \\
$\begin{array}{l}\text { Believed ECP is safe } \\
\text { Effectiveness }\end{array}$ & 88.0 & 97.9 & 84.3 & 85.7 \\
$\begin{array}{l}\text { Very effective } \\
\text { Somewhat/not } \\
\text { effective }\end{array}$ & 72.3 & 81.8 & 86.8 & 82.4 \\
Do not know & 26.5 & 12.1 & 7.6 & 13.1 \\
\hline Total (N) & 1.2 & 6.1 & 5.6 & 4.5 \\
\hline
\end{tabular}

Questions about ECP's medical contraindications revealed various misconceptions and a lack of correct knowledge among providers. According to WHO's Medical Eligibility Criteria, ECP is safe in all conditions, except pregnancy (WHO, 2009). Less than 2 percent of providers stated that there are no conditions under which ECP is unsafe, and many doctors and other paramedics held misconceptions that ECP cannot be taken by women suffering from heart disease or who are breastfeeding (Table 11). Over one third of providers, including over half of pharmacists, reported a lack of knowledge on ECP medical eligibility criteria.

Table 11: Knowledge of ineligibility criteria (ECP use) (percent)*

\begin{tabular}{lcccc} 
Condition & Qualified doctors & Other providers & Pharmacists & Total \\
No medical conditions & 3.6 & 0.0 & 0.5 & 1.3 \\
Pregnancy & 59.0 & 48.5 & 31.2 & 40.3 \\
Liver diseases & 45.8 & 33.3 & 10.1 & 21.9 \\
Heart diseases & 37.3 & 42.4 & 12.6 & 22.2 \\
Breastfeeding & 26.5 & 15.2 & 6.0 & 12.4 \\
Weakness/nausea/lack & & & & \\
of hemoglobin/others & 1.2 & 6.1 & 3.5 & 1.9 \\
Do not know & 0.0 & 30.3 & 52.8 & 36.5 \\
\hline Total (N) & 83 & 33 & 199 & 315
\end{tabular}

*Percentages add more than 100 because of multiple responses 


\section{Knowledge of side effects}

Sixty percent of the providers ( 90 percent doctors, 67 percent paramedics and 46 percent pharmacists) said that ECP has no side effects. Providers reported light vaginal bleeding ( 66 percent), fatigue ( 35 percent), nausea (33 percent), vomiting ( 26 percent), abdominal pain (15 percent), and headache (15 percent) as possible short term side effects or do not know.

\section{Provider attitudes of ECP provision as OTC or prophylactic drug}

A little more than half (55 percent) of the providers agreed that women should be provided ECP as prophylactic so that it could be used when required while 26 percent opposed it (Table 12). However, more doctors than other providers and pharmacists did not support providing ECP on a prophylactic basis. A logistic regression analysis showed that male providers were three times more likely than female providers $(\mathrm{OR}=3.51, \mathrm{p}<0.05)$ to support provision of ECP on a prophylactic basis, as were younger providers $(\mathrm{OR}=1.93, \mathrm{p}<0.01)$, those who had ever received training in FP $(\mathrm{OR}=1.99, \mathrm{p}<0.05)$ and those who had ever received any brochures or other educational materials on ECP $(\mathrm{OR}=2.37, \mathrm{p}<0.05)$. Those who opposed the provision of ECP as prophylactic had fear that it may increase its misuse either to use it as a regular method or increase premarital sex and promiscuity.

\section{Table 12: Provider attitudes and beliefs about ECP access and availability (percent)}

\begin{tabular}{|c|c|c|c|c|c|}
\hline & & Qualified doctors & Other providers & Pharmacists & Total \\
\hline \multirow{3}{*}{$\begin{array}{l}\text { Should } \\
\text { women be } \\
\text { provided } \\
\text { with EC in } \\
\text { advance } \\
\text { of sex? }\end{array}$} & Yes & 48.2 & 57.6 & 58.1 & 55.4 \\
\hline & No & 42.2 & 27.3 & 19.7 & 26.4 \\
\hline & $\begin{array}{l}\text { Do not } \\
\text { know }\end{array}$ & 9.6 & 15.2 & 22.2 & 18.2 \\
\hline \multirow{4}{*}{$\begin{array}{l}\text { Should EC } \\
\text { be available } \\
\text { OTC without } \\
\text { prescription? }\end{array}$} & Yes & 29.3 & 39.4 & 60.6 & 50.2 \\
\hline & No & 67.1 & 60.6 & 34.3 & 45.7 \\
\hline & 1t aеperius & 1.2 & 0.0 & 0.5 & 0.6 \\
\hline & $\begin{array}{l}\text { It is already } \\
\text { an OTC drug }\end{array}$ & 2.4 & 0.0 & 4.5 & 3.5 \\
\hline Total (N) & & 83 & 33 & 199 & 315 \\
\hline
\end{tabular}


A similar probing on whether ECP could be provided OTC shows that more doctors and other trained providers than pharmacists were against provision of ECP as an OTC drug. A logistic regression analysis showed that male providers were three times more likely than female providers $(\mathrm{OR}=3.5, \mathrm{p}<0.01)$ to support availability of ECP as an OTC drug. No other characteristics showed any significant difference on provision of ECP as an OTC drug, though generally less than one-third of the doctors supported provision of ECP as an OTC drug.

\section{Access, stock out and other challenges in providing ECP}

Most (97 percent) providers were of the opinion that ECP is easily accessible to all women who want to buy it. However a few felt that cost (9 percent), lack of awareness (5 percent) and shame or hesitation ( 2 percent) could pose as barriers to access for some women.

Slightly less than half (44 percent) of providers, mainly from NGOs and urban public health FP clinics, as well as pharmacists mentioned occasional stock outs, while 35 percent of all providers said they never experience any stock outs. Ninety-two percent of providers said they do not have any ECP supply problems. However, only 30 percent of providers felt all ECPs currently available in the market are of good quality, and 32 percent felt ECP's current cost is affordable.

\section{Preferred ECP providers}

When asked who should provide ECP, the spontaneous answers mentioned most frequently were; qualified doctors (96 percent), followed by pharmacists (63 percent). Only a quarter of providers interviewed mentioned nurses or midwives, and still a smaller percent (16 percent) mentioned CHWs or local TBAs or village doctors (5 percent) as preferred sources of ECP.

A separate direct question on whether CHW/AWW should be allowed to provide ECP, 53 percent doctors, 36 percent other providers and 19 percent pharmacists were not in favor of CHWs / AWW providing ECP because it may increase its misuse (43 percent), many do not have adequate knowledge of ECP and need prior training (34 percent) etc. In rural areas, CHWs such as ASHAs and (unqualified) village doctors could play a significant role in ensuring easy ECP accessibility to all who need it. Nevertheless, this study's findings show that more than half of doctors are still resistant to ECP provision through CHWs or other non-medical providers.

Bivariate analysis further suggests that a significantly higher proportion of male providers (74 percent) than female providers (46 percent) agree with making ECP available to all women through CHWs ( $z$ test, $\mathrm{p}<0.01)$. 


\section{Characteristics of ECP seekers}

Most providers mentioned that the majority of women seeking ECP from them are between 20 to 29 years old, with one-third of providers reporting women aged between 30 and 39 years old (Table 13). Ten percent of providers reported providing ECP to women under 19, primarily by pharmacists. As to be expected with these age profiles, the majority of providers reported most ECP clientele as married, while nearly half reported unmarried or student clientele. A small proportion of providers also mentioned men approaching them for ECP information or other services.

Table 13: Impressions of providers who use ECP (percent)*

\begin{tabular}{|lcccc}
\hline Age range seeking ECP & Qualified doctors & Other providers & Pharmacists & Total \\
\hline$<=19$ years & 1.2 & 3.0 & 15.6 & 10.5 \\
20-29 years & 68.4 & 74.2 & 81.9 & 77.7 \\
30-39 years & 39.2 & 58.1 & 31.7 & 36.2 \\
$>=40$ years & 0.0 & 6.5 & 2.5 & 2.3 \\
Women of all ages & 2.5 & 0.0 & 6.0 & 4.5 \\
\hline Total (N) & 79 & 31 & 199 & 309 \\
\hline ECP Seekers' Status & & & & \\
\hline Married women & 68.4 & 87.1 & 55.8 & 62.1 \\
Students/unmarried women & 20.5 & 30.3 & 60.3 & 46.7 \\
Women of all ages & 15.2 & 3.2 & 28.1 & 22.3 \\
Men & 5.1 & 3.2 & 13.6 & 10.4 \\
\hline Do not know & 2.5 & 0.0 & 2.5 & 2.3 \\
\hline Total (N) & 79 & 31 & 199 & 309 \\
\hline
\end{tabular}

*Based on those currently providing ECP

When asked about the characteristics of repeat ECP users, only 9 percent providers said that they are different from single users, 41 percent said no and 50 percent said cannot say or don't know. Some of the different things about ECP users reported were; they seem physically unfit (16 percent), always look tired (13 percent), are unaware of repeat use side effects (16 percent), have menstrual problems (26 percent), have multiple sex partners ( 13 percent) etc.

\section{Attitude towards sexual and contraceptive behavior ECP user's}

The providers were asked various questions on their perception of how ECP could influence contraceptive and sexual behavior of women. Around half of the providers 
interviewed believed that easy access to ECP would increase the promiscuity of women and men. Still lower ( 66 percent) felt that it could encourage premarital sex. Fifty three percent doctors, 55 paramedics whereas a striking 74 percent pharmacists said that ECP users engage in premarital sex. Other risk behaviors mentioned by above one fourth of the providers include engagement in premarital sex and belief that easy access will increase promiscuity. About one third also felt that some couples might start using as a substitute to other regular family planning methods. (Table 14).

\section{Table 14: Attitudes of providers towards ECP user's sexual behavior (percent)}

\begin{tabular}{|c|c|c|c|c|}
\hline Attitude & Qualified doctors & Other providers & Pharmacists & Total \\
\hline \multicolumn{5}{|l|}{ Believed easy access will } \\
\hline increase promiscuity & 45.1 & 59.4 & 46.0 & 47.1 \\
\hline \multicolumn{5}{|l|}{ Increase participation in } \\
\hline risky sexual behaviors & 18.3 & 24.2 & 28.3 & 25.2 \\
\hline Have more sexual partners & 25.9 & 39.4 & 27.2 & 28.2 \\
\hline \multicolumn{5}{|l|}{ Have sexually } \\
\hline transmitted infections & 29.3 & 24.2 & 28.3 & 28.1 \\
\hline Engage in premarital sex & 53.1 & 54.5 & 73.7 & 66.3 \\
\hline Substitute other methods & 39.0 & 30.3 & 31.8 & 32.9 \\
\hline Total (N) & 83 & 33 & 199 & 315 \\
\hline
\end{tabular}

\section{Repeated use}

More than three-fourths of doctors, along with almost half of other providers and one third of pharmacists, felt ECP should not be used repeatedly in the same menstrual cycle. Large proportions of pharmacists and providers other than doctors did not know whether ECP could be used repeatedly in the same menstrual cycle (Figure 2).

Among the 41 providers who felt ECP could be used more than once in the same cycle, the majority recommended a limit of two times during the same menstrual cycle. About three-fourths ( 72 percent) of pharmacists and more than half (57 percent) of doctors believe that "many women" use ECP repeatedly.

Among the providers, most (46 percent) either did not favor the use of ECP several times within the same menstrual cycle or were not sure (40 percent). Only 14 percent $(\mathrm{N}=44)$ approved its repeat use in the same menstrual cycle. Out of 44 who approved 
repeat use, 21 approved two times, 16 more than two times while 7 were not sure of the number. Those who disapproved repeat use of ECP in the same menstrual cycle, most of them were doctors (82 percent).

Figure 2: Providers' opinions on repeated use within one menstrual cycle (percent)

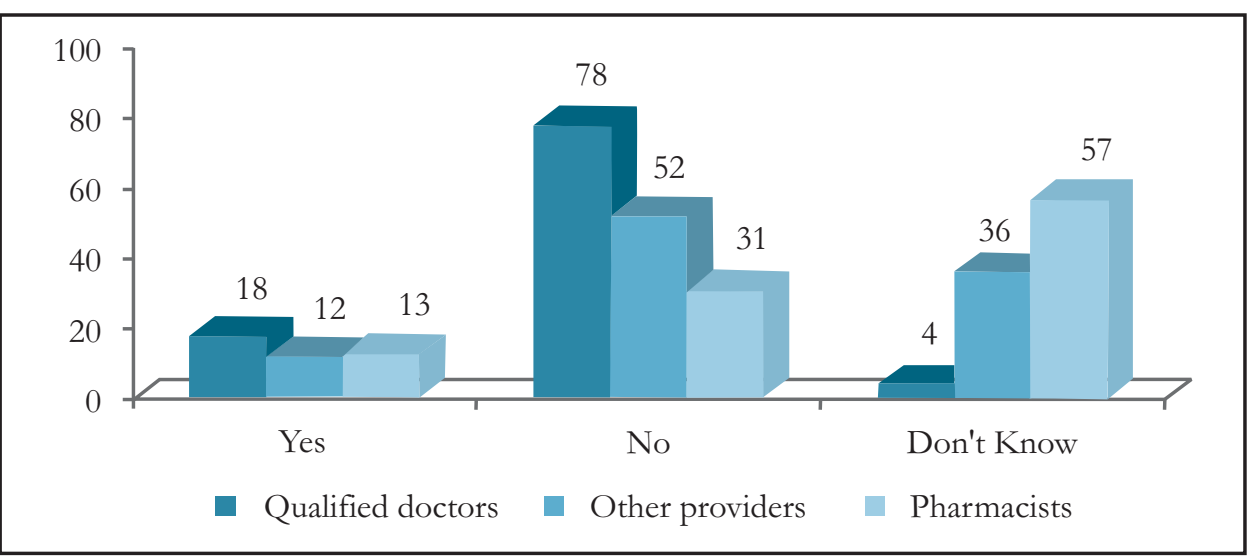

An analysis by category of providers shows that most (78 percent) doctors disapproved repeat use of ECP (i.e. use more than once in the same menstrual cycle). The corresponding figure for paramedics was 52 percent, 32 percent for pharmacists. However, those who were not sure whether ECP could be used repeatedly within the same menstrual cycle were largest among pharmacists (13 percent) followed by doctors (7 percent) and no paramedics.

Two-thirds of pharmacists (131 of 199) have provided ECP to the same woman more than once, but not necessarily in the same cycle, while only 16 percent of doctors (out of 83 ) and 24 percent of other providers (out of 33) reported doing so. Furthermore, over half (56 percent) of all providers said a small proportion (10 percent) of women who come to them have taken ECP before. A substantial proportion (14 percent) of the 131 pharmacists reported that more than 30 percent of women they serve have received ECP from them more than once (Table 15).

Table 15: Percentage of women buying ECP more than once (percent)

$\begin{array}{lcccc}\text { Percent } & \text { Qualified doctors } & \text { Other providers } & \text { Pharmacists } & \text { Total } \\ 1-10 & 84.6 & 75 & 52.7 & 56.6 \\ 11-20 & 7.7 & 12.5 & 26.7 & 24.3 \\ 21-30 & 7.7 & 12.5 & 6.9 & 7.2 \\ >=31 & 0.0 & 0.0 & 13.7 & 11.8 \\ \text { Total (N) } & 13 & 8 & 131 & 152\end{array}$


Need for guidance on repeated use: Slightly less than half (44 percent) of providers felt there should be guidance on the number of times a woman could use ECP in the same month, but opinion varied widely; 70 percent of doctors, 49 percent of other providers, and 33 percent of pharmacists believed guidance on repeated use should be provided.

\section{ECP users' preferred brands}

Figure 3 shows, among different ECP brands on the market, Unwanted-72 (82 percent) and $I$-pill (74 percent) are the two most commonly provided.

Figure 3: Types of ECP dispensed by providers (percent)*

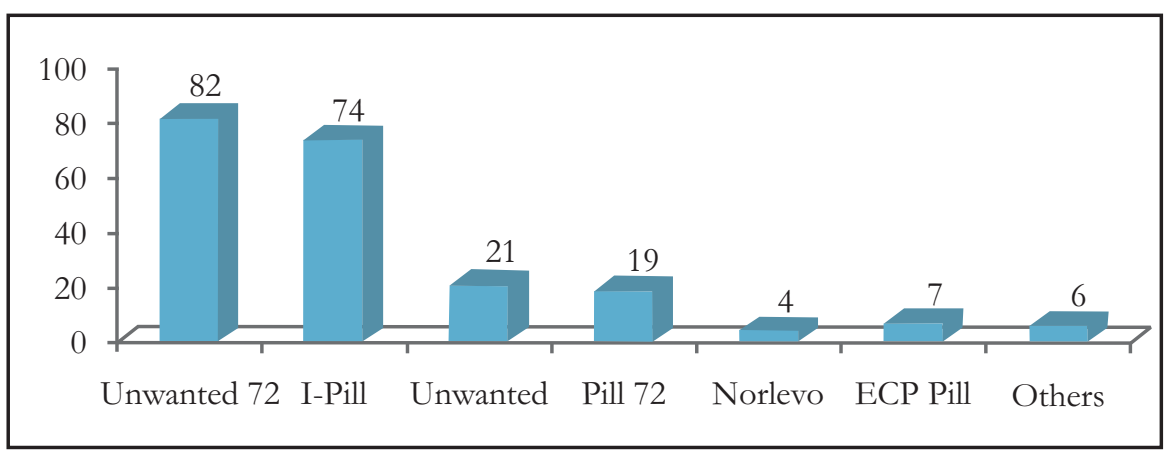

*Percentages may not add to 100 because of multiple responses: Based on *309 currently providing ECP.

Table 16: Service and information provided to customers requesting ECP (percent)*

\begin{tabular}{lcccc} 
Information provided & Qualified doctors & Other providers & Pharmacists & Total \\
\hline Simply ECP & 2.5 & 12.9 & 93.5 & 62.1 \\
General information & 51.9 & 54.8 & 4.5 & 21.7 \\
How to use & 46.8 & 32.3 & 2.5 & 16.8 \\
When to use & 53.2 & 35.5 & 2.0 & 18.4 \\
About side effects & 34.2 & 22.6 & 1.0 & 11.7 \\
Counsel on FP & 17.7 & 3.2 & 0.5 & 5.2 \\
Counsel on STI/HIV/ & & & & \\
respond/refer to & 16.5 & 9.7 & 2.5 & 6.8 \\
other services & 79 & 31 & 199 & 309 \\
\hline Total (N) & & & &
\end{tabular}

*Based on those currently providing ECP 


\section{Information provided to customers requesting ECP}

As seen in Table 16, 9 out of 10 pharmacists reported simply providing ECP to customers. Half of doctors said they provide general information on ECP, and were more likely than other providers and pharmacists to explain when and how to use ECP, its various side effects, and to counsel them on other FP methods

\section{Provider suggestions for increasing ECP knowledge}

A large majority ( 80 percent) of providers have observed a need for more media campaigns increasing public awareness of ECP. Providers recommended more advertisements on television (42 percent), mid-media campaigns, and meetings or posters (19 percent) to build ECP's image as backup support for temporary FP methods. Awareness campaigns disseminating accurate ECP knowledge through health workers and doctors were also suggested.

\section{Findings from key opinion leaders}

\section{Knowledge of mechanism of action}

All 8 gynecologists knew ECP's mechanism of action, stating that ECP works by delaying or inhibiting ovulation, as is reflected in the following quote:

"The precise mechanism of how ECP works in a particular case is unknown. The action of ECP depends on time taken (after unprotected sex) and the stage of menstrual cycle. The mechanisms of action are that ECP delays ovulation, thickens the cervical mucus, directly inbibits fertilization and alters transportation of egg and the sperm." - Senior gynecologist, public hospital

Uncertainty and ambiguity about ECP's mechanism of action persists among providers; for instance, ECP's effect if taken after ovulation or implantation was unclear to many. One doctor stated:

"The exact mechanism of action is not known. But it mainly prevents ovulation and it depends what day of a menstrual cycle ECP is taken." - Senior official, Indian Medical Association

Most KOLs (8) clearly mentioned that ECP is not an abortificant. From the discussions, it seems that none of the KOLs mistook ECP as an abortificant.

\section{Safety}

All 19 KOLs regarded ECP as safe, with eight stating that ECP is safe but with minor side effects: 
"There are no health hazards with this pill, because it is a progesterone pill; and progesterone is a hormone in the body. You will not have any major problem if you take EC, apart from menstrual irregularity and maybe some breast tenderness and abdominal pain." —Senior official, National Family Welfare Program

"There are not major issues concerning safety, except that some clients may experience minor side-effects, but there are no major side-effects." —Program manager, international donor agency

\section{Effectiveness}

Six KOLs stated that ECP's effectiveness is more than 90 percent, with two stating more than 80 percent effectiveness, and one mentioning 60 to 80 percent effectiveness; the remainder mentioned that ECP is "very effective" but did not give an exact number. Six medically-trained informants, however, mentioned that ECP's effectiveness varies according to whether it is taken before or after ovulation, and how long after sex:

"The effectiveness of ECP is time bound. If you take it in the first 24 hours it is very effective and if you take it in the next 24 hours it is less effective. In general if you take it within 72 hours, I would say it is 85 percent effective." - Senior gynecologist, private hospital

\section{Attitudes towards ECP}

Appropriate ECP use: Eight of 19 KOLs stated that the most common situation in which ECP could be used was contraceptive failure:

"No contraceptive method is 100 percent effective. So you need a backup method like ECP, in case a woman misses a pill, or there is condom rupture." - Senior gynecologist, public hospital

ECP was also regarded as appropriate for women who have infrequent sexual intercourse:

"It is a better option for women whose husbands are migrants." —Program manager, international donor agency

"T think unmarried girls who are exploring their sexuality and having infrequent sex with their boyfriends can use it." - Senior gynecologist, private hospital. 
Less than half (7 of 19) felt ECP is appropriate for all women, irrespective of marital status and age:

"There is nothing like that ECP is appropriate for certain kinds of women. It is for all women." - Senior official, Indian Medical Association

Link with promiscuity and premarital sex: Only 3 KOLs linked increasing ECP's access to promiscuity and premarital sex. For most KOLs, it was either a misconception, or they stated that premarital sex will occur with or without ECP, although 6 were unsure or did not directly disclose an opinion:

'I don't think there is any correlation between promiscuity and premarital sex. People will continue to what they want to do, but this comes as a handy tool in certain situation. ECP is what it says ... it is an emergency contraceptive pill ... it is for an emergency." —Senior program manager, pharmaceutical manufacturing company

\section{Belief that ECP will supplant regular contraceptive methods}

Half of KOLs said increased ECP availability will not make it a substitute for regular methods, as those using a method regularly will continue and not switch to ECP, if they are satisfied with their regular method; the cost of repeated ECP use is higher, and it is less effective. Two gynecologists and 1 FP officer mentioned that most clients switch to regular methods after using ECP because of counseling, but in their experience, a few do not transition to regular methods, primarily because of misconceptions about regular methods, or because their partners do not want to use condoms or they find ECP more convenient because they have irregular sexual intercourse:

"In my experience, if 10 women have taken EC and are counseled for regular method use after that, then eight would go for regular method while two would not. The main reasons why they do not want to use a regular method are because of misconceptions, like their weight will increase if they take OCPs or it may cause cancer." - Senior gynecologist, public hospital and senior official, Indian Medical Association

Conversely, 8 of 19 KOLs expressed fear that increasing access to ECP will encourage people to abandon regular contraceptive methods:

"Personally I am against ECP. I do feel that it would result in the substitution of mala-D and condoms which is the best choice in case of contraceptives." - Senior program officer, State Health Resource Center 


\section{Reservations among providers and program managers}

Half of KOLs said that doctors and paramedics may have some reservations in providing ECP. Three KOLs believed ECP requires a lot of counseling for countermanding its misuse and that doctors do not have the time, so they are not able to promote it actively:

"Our doctors have no time or habit of counseling on ECP or any health issue for that matter."-Program manager, national health and FP NGO

Three informants said, since ECP is easily available and accessible as an OTC drug, women misuse it, as a regular FP method, and then rush to the gynecologist when it is too late, either when they have become pregnant or their menstrual cycle has become irregular. Hence, even if ECP is an OTC drug, it was felt that women who use it should visit a gynecologist after use.

A few gynecologists and a top state family welfare officer believed ANMs should not promote ECP because of its potential misrepresentation as an abortion pill:

"Some gynecologists have personally told me that they feel ANMs should not promote ECP because they will misuse it. They fear that as ANMs do private practice and they may sell the [free] ECP as an abortion pill. Nor ANMs are trained enough to provide it." - Senior program manager, State Family Welfare Program

Two mid-level state program officers mentioned that the Government's FP program is perceived as low priority, even by top officials and, hence, many important activities are neglected. For example, no one has inquired about how ECP is being introduced in rural areas, nor how ANMs or ASHAs have been oriented on ECP. A program manager from a large donor agency felt that government officials may also have reservations about increasing ECP access because of moral issues or indifference about the method:

"There might be some individuals [in the government] who might be skeptical of promoting ECP, having the notion that it would promote promiscuity. We know that easy access of ECP does not promote promiscuity but some government officials might be holding value judgments. If higher level officials don't talk about it, then the message goes down the line." -Program manager, UN agency

\section{Perception of KOLs about ECP users}

KOLs felt that government hospital clients are mostly married women, parity one and 
two, under 30, and of lower income, with most using ECP either because of method failure or infrequent relations with their husbands:

"Women whose husbands are not living with them come to us for ECP. Their husbands are posted in Tamil Nadu or and come infrequently to Delhi. They use EC pills. Ours is a government set up, most of the women who come are mostly married middle class women." -Senior gynecologist, public hospital and senior official, Indian Medical Association

Clients at large private hospitals are generally single, sexually active women, between the ages of 18 to 26 (i.e. unmarried), from the upper middle and upper class, well educated, and with infrequent sexual intercourse. Many face menstrual-related problems or have failed to protect themselves from pregnancy. Most unmarried women from lowermiddle income groups go to private clinics if they can afford the cost. Some KOLs consider ECP as a symbol of women's empowerment. A senior gynecologist stated:

"I believe it is a very safe product and it empowers the woman and it's a felt need. They only come to me when they face some problem" - Senior gynecologist, private hospital

\section{Attitudes towards repeated use}

Definition of repeated use: As shown in Table 17, over one-third of KOLs could not say how many times ECP can be taken in a menstrual cycle before considered as repeated use. Almost all KOLs interviewed were concerned about repeated use. They were of the view that ECP is for emergency and should be a last effort to protect from unwanted pregnancy.
Table 17: Definition of repeated ECP use, reported by key opinion leaders

\begin{tabular}{|cc|}
\hline $\begin{array}{c}\text { Number of times in a month } \\
\text { qualifying as repeated use }\end{array}$ & Frequency \\
\hline 1 & 5 \\
2 & 4 \\
3 & 3 \\
Can't Say* & 7 \\
\hline Total (N) & 19 \\
\hline
\end{tabular}

*Includes 1 missing case

Fear of ECP repeated use: One of the biggest concerns often expressed, with as many as 13 of the 19 KOLs expressing serious concern, is that ECP is not being used as an emergency pill, nor is it advertised or promoted as such:

"If a woman is taking ECP five times it means she needs to use a regular contraceptive. The amount of progesterone taken in five times of ECP use is more than the one month's pack of OCP. The client needs to understand this; moreover, suspecting unwanted pregnancy five 
times a month means a lot of stress and tension. If she is taking it once every month and then it is not an emergency either. ECP is for real emergency." - Senior gynecologist, public hospital and senior official, medical association

"An emergency does not repeat frequently. If you put your hand in the fire, you don't do it again, do you? W by talk about repeat use? We can't keep talking about how many times to use it repeatedly. You can't get in to an emergency every now and then. We have to talk about ECP in a different fashion. This is an emergency pill- the message should be to use it during an emergency and then go on to a routine method." - Senior official, National Family Welfare Program

\section{Over the counter ECP provision}

Five KOLs voiced concerns about making ECP an OTC drug:

'I strongly feel that ECP should be distributed only through doctor's prescriptions. It should not be available over the counter for anyone to buy. That is how it is being hugely misused. Anyone anytime could go and ask and buy it from a chemist any number of times." - Senior program officer, State Health Resource Center

"Repeat use of ECP is a concern when we are trying to expand the use of OCPs and condoms. ”- Program manager, international donor agency

Gynecologists reported that women come to them either with side effects (irregular bleeding) or pregnancy, as it is easily available as an OTC drug, they may use it regularly. Gynecologists' main concern is their lack of opportunity for counseling women since ECP is an OTC drug. As a gynecologist put it:

"My only issue is that there should be a rider on ECP pack that the client should follow up with a gynecologist within 15 days of taking it, and then we can counsel women on the failure rates. What usually happens is that it is a progesterone pill and the user has a little bit of bleeding and confuses it as a normal period. But actually they have missed their period and when they come to us, they come with an advanced pregnancy." - Senior gynecologist, private hospital

Four KOLs said that if ECP is an OTC drug, public awareness about its proper use is needed. Providers should be adequately trained and ECP packaging should be properly informative or a proviso should recommend users see a gynecologist after selfadministering ECP. 


\section{Could ECP help decrease abortions?}

Many gynecologists (6 of 9) said it seems logical that increasing ECP's access could have led to a decline in abortions; they felt sure that the number of surgical abortion has decreased but did not have supporting statistics. For example:

"The number of young girls who used to come for abortion has declined. In my own clinic, there used to be two to three girls every week. with unwanted pregnancy for abortion and they would be 10 to 12 weeks pregnant. Now in a month we hardly see one such girl. So ECP has prevented unwanted abortions"-Senior gynecologist, famous private hospital

"Surgical evacuations have gone down a lot. One is because of ECP and second because we are giving them medical abortifacient. The number of surgeries we are doing has drastically dropped. But we cannot say if it is because of ECP or the MTP pill." - Senior gynecologist, private hospital

\section{Supply, demand, and access}

Barriers to women's access: Five KOLs stated that there are no barriers to women's ECP access:

$$
\begin{aligned}
& \text { "Getting ECP is not a problem as it is an OTC drug. You can go to an unknown chemist if } \\
& \text { you want privacy. Even the cost [of Rs. 100] is not much." - - Senior gynecologist, } \\
& \text { public hospital }
\end{aligned}
$$

Many KOLs (7) believe the main barrier is a lack of real ECP knowledge and its correct use. Some said that there is no awareness among rural women that ECP exists. Three informants mentioned that, in smaller towns and villages, the fear and stigma associated with acquiring ECP also poses a barrier:

"There is stigma and fear attached to access EC. If a woman wants to get ECP and does not want her husband to know, then how will she ask for it? She will think whatpeople will say. It is important to take health workers in confidence."-Senior official, Indian Medical Association

Two KOLs mentioned there has not been enough providers training, which prevents access, while another 2 said cost also restricts ECP access.

Provider challenges: Several challenges were reported, including lack of knowledge, inadequate training, difficultly in identifying clients, and counseling them, meager motivation, and poor supply in public clinics. Over half the KOLs said providers, including doctors, pharmacists, ASHAs and ANMs, do not have accurate ECP 
knowledge nor have been adequately trained to provide ECP and related services; it should be noted that no ECP training was offered when introduced by the Government:

"All the training guidelines have been developed for ASHAs, but somebody has to take the pain to train them and explain them about ECP and monitor usage. You are talking about eight lakhs ASHAs and thousands of trainers, so training looks like an issue." -Program manager, UN agency

"None of the ANMs have got any training on ECP, they learnt by practice and by working with us and discussing with us. There has been no training given to any doctors or ANMs or to the pharmacists. It is also not there in the service guidelines of doctors or ANMs. Then how will anyone know about the exact or the appropriate use of ECP?"-Gynecologist, urban family planning clinic

"The pharmacists are not trained and they just give ECP on demand. How will they counsel and give correct information to the client?" - Senior gynecologist, private hospital

Four program managers reported that ECP, and even FP, provision has not been a focus of the Ministry of Health and Family Welfare:

"Family planning has never been a focus. No bigh profile official wants to inaugurate meetings of the family planning program. ECP has not been a focus since it was never there in supply. Now it has come back and the supply is picking up. People are asking for it. FP is low priority in the State health system" - Senior program manager, State Family Welfare Program

Five informants mentioned that there is little chance for ECP counseling, either because doctors are not in the habit or because it is purchased OTC without doctor consultation. Nine KOLs mentioned special challenges for increasing access to ECP in rural areas:

"In rural areas people have to travel $10 \mathrm{kms}$ to reach a pharmacist, unlike in urban areas. There is no bus or any transport to reach there. Cost is also a barrier. Also there is a certain degree of anonymity in urban areas but in rural areas everyone will come to know if you are buying ECP. It is a challenge to reach these groups.” - Program manager, national health and FP NGO 


\title{
Opinions on government program to make ASHA the depot holder of ECP
}

In general, program managers welcomed GoI's pilot project to make ASHAs contraceptive depositories for community supply at a small cost. While one informant believed that charging Rs.2 for ECP from ASHAs (instead from health facilities for free) may compromise access for those in dire need of ECP who may not be able to buy it. Another informant said that the price is not much and that making ASHAs depositories will increase ECP accessibility. The Government's ASHA pilot project was seen as focusing on spacing methods:

\begin{abstract}
"For the first time the government is going with a spacing package. It is a deviation from the earlier approach which focused on permanent methods. The supply will be at the district level and will not be withdrawn from there. The cost of Rs.2 for ECP is not much-money is not a big dampener. But training has to be done, a communication plan should be there and proper monitoring has to be done." - Program manager, UN agency
\end{abstract}

\section{KOLs' suggestions for increasing access}

As shown in Box, the key recommendations for increasing ECP access were the development of a communication plan and use of mass media for disseminating information to the public, particularly on repeated use, side effects, and emergency use only. It was also suggested that doctors, pharmacists, and CHWs providing ECP need to be adequately trained.

Box: Key recommendations for
increasing ECP access
- BCC plan including mass media
- Adequate training of pharmacists
- Adequate training of ASHAs
- Regular and frequent updates on ECP for
government officials
- ECP should be included in refresher
courses for ANMs
- Sensitize mass media to project ECP
correctly.

Other suggestions for increasing access

to ECP include frequent ECP updates circulated among government officials, inclusion of ECP information in all ANM and ASHA refresher courses, partnerships with rural private providers, and other forms of media including door-to-door counseling, IEC, and VHNDs for disseminating ECP information. The focus should be on adolescents and young people who can be reached through programs, sex education classes at school, the mass media and other forms of media (e.g. internet). Only one KOL said that ECP should be made available only on doctor's prescription and not as an OTC drug. 


\section{KOLs' suggestions for advertising}

The key advertising message, according to 13 KOLs, should be ECP's use for emergency situations only. ECP should be promoted along with other contraceptive methods and not as a separate method, in mass media. It should be a backup to method failure and with repeated use's side effects given more attention. KOLs believe sex should be projected as a responsible and not casual activity for which ECP is readily available; informants said that this was one of the reasons why recent commercial advertisements were banned or withdrawn. Central government officials stated that ECP is being advertised in mass media, but state officials said it has yet to begin at their level. Many KOLs reiterated that a responsible role by media can help increase correct ECP information and knowledge; the media needs to be sensitized:

"[nitially] ECP was being advertised as something very attractive to use. But it is not like that. The way we create awareness, educate and counsel the public and the providers is very important. It should be done in such a way that it is something that should be used only in accidents or emergency. It should not be advertised as a contraceptive method." - Senior gynecologist, public hospital

"The media is glorifying sex and making it sounds like a casual thing. It projected 'let's go have sex and take ECP after that'. They did not give the whole message and trivialized issue of unwanted pregnancy and risk of unsafe sex. Creating hype is the easiest thing to do. The media needs to show sex as a responsible behavior. We need sustained mass media, mid media and IPC to spread correct information to the public." - Senior official, National Family Welfare Program

\section{Conclusions and recommendations}

This study's findings show that most providers, including doctors and some KOLs, were incorrectly informed about ECP's mechanism of action. Many doctors still believe ECP prevents implantation and cannot be used by breastfeeding women or those with heart problems. Pharmacists, who provide most of India's ECP, are the most uninformed group of providers. As a consequence of pharmacists' lack of knowledge of ECP, they do not provide any information on it to customers, in addition to fear of embarrassing customers because of lack of privacy in their shops, in addition to lacking time for any real client counseling. It is encouraging that all categories of providers and KOLs generally believe ECP is safe and effective for preventing unwanted pregnancies. Most providers are still reluctant to provide or promote ECP as a prophylactic, and most KOLs said ECP is only appropriate for emergencies such as contraceptive failure or infrequent or isolated sex acts. Most providers believe ECP is 
best and most appropriate for married women and that a minimum age restriction of 18 to 20 should be instituted for ECP provision. The stigmatization of ECP makes its accessibility difficult and belies a general fear among providers of 'misuse' by young, unmarried women.

Among all providers, ambiguities persist about the definition of repeated use during the same menstrual cycle. In general, repeated use of ECP was not acceptable among providers, including pharmacists, the primary providers of ECP, who believe many women use it repeatedly; pharmacists, compared to other providers, report more frequent, repeated ECP use by their clientele. Correct ECP use, including as a back-up method, depends largely on how knowledgeable users are, and in the absence of such knowledge incorrect use may cause menstrual disorder or pregnancy prevention failure. Service guidelines are necessary for accurate and adequate information on ECP's mechanism of action, as well as its use as a back-up or emergency method, its frequency of use in the same menstrual cycle, and its lack of effectiveness and possible side effects if used repeatedly.

Most KOLs supported ECP's continuation as an OTC drug, but some KOLs and many qualified doctors had reservations about promoting or mainstreaming ECP with other contraceptive methods; these same providers were also less supportive of its OTC status as well as its distribution by CHWs such as ASHAs. In general, doctors do not agree with ECP's de-medicalization and would prefer it to be a prescription drug, which is a matter of concern requiring advocacy to influence and change their opinions. Disseminating accurate ECP information among all provider categories could be achieved, to some extent, by including ECP in the training curricula of all doctors, nurses, and pharmacists. Periodic seminars and presentations through the official organizations of different providers such as the Indian Council of Medical Research (ICMR), Federation of Obstetrics and Gynecological Societies of India (FOGSI), or Indian Pharmacists Association could also help mitigate misconceptions about ECP and improve dispensing practices for it.

The most important rationale for ECP's introduction and funding is that it's easy access and correct use will reduce unwanted pregnancy and abortion. IDIs with doctors, however, belied their uncertainty about whether women are benefiting from ECP. Several senior gynecologists mentioned that ECP has helped reduce the rate of unwanted pregnancies and abortions, especially among young women, but they also stated this decline could be attributed to easy availability of medical abortion pills.

Some providers and KOLs felt ECP's benefits are undermined by irresponsible advertisements that result in misuse. There is a general feeling that young people are 
becoming more open to premarital sex, in which case ECP can prevent unwanted pregnancy, but it can be misused easily with increasing frequent use, for example half of the providers felt that easy accessibility may also lead to promiscuity. Most KOLs believe the relationship between ECP use and promiscuity is a misconception, although some do believe they are related. There is also concern that ECP may be substituted for regular contraceptive methods, but many KOLs believe it can act as a bridge to regular methods, if promoted correctly.

Manufacturers, pharmacies, and some KOLs want the Government to rescind the ban on ECP advertising but emphasize that advertisements should emphasize ECP's "emergency only" use. ECP advertisements should emphasize its emergency utilization, when another method fails, rather than as a separate method. Several experts suggested responsible advertising through mass media and promoting ECP along with other contraceptive methods would help improve its perception as a backup method among the general public and reduce misuse. Emphasizing that 'any woman in an emergency situation can use ECP' will also help reduce its stigma and the labeling of its users. As part of corporate social responsibility, medical representatives of different ECP manufacturing firms in regular contact with pharmacists could play a significant role in educating pharmacists about ECP and its overall role as an emergency device for protecting against unwanted pregnancy, and not as a regular method or abortifacient. 


\section{References}

Aksu, H. O., Başak, M. K., Yeniçeri, N., \& Kaya, S. (2011). Emergency contraception: Knowledge, attitude and practice of the pharmacy staff in Aydin, Turkey. Clinical and Experimental Obstetrics and Gynecology, 38(3), 260-264.

Bhatnagar, I., \& Khan, M. E. (2011). Increasing acceptance of spacing methods in rural Bihar: Implications for behavior change communication. Policy Brief 5. New Delhi, India: Population Council.

Blanchard, K., Harrison, T. \& Sello, M. (2005). Pharmacists' knowledge and perceptions of emergency contraceptive pills in Soweto and the Johannesburg central business district, South Africa. International Family Planning Perspectives, 31(4), 172-178.

Camp, S. L., Wilkerson, D. S., \& Raine, T. R. (2003). The benefits and risks of over-thecounter availability of Levonorgestrel emergency contraception. Contraception, 68, 309-317.

Croxatto, H. B., Brache, V., Pavez, M., Cochon, L., Forcelledo, M. L., Alvarez, F., Massai, R., Faundes, A., \& Salvatierra, A. M. (2004). Pituitary-ovarian function following the standard Levenorgestrel emergency contraceptive dose or a single $0.75 \mathrm{mg}$ dose given on the days preceding ovulation. Contraception, $70,442-450$.

Ehrle, N., \& Sarker, M. (2011). Emergency contraceptive pills: Knowledge and attitudes of pharmacy personnel in Managua, Nicaragua. International Perspectives of Sexual and Reproductive Health, 37(2), 67-74.

Goel, S., Bhatnagar, I., Khan, M. E., \& Hazra, A. (2010). Increasing postpartum contraception in rural Uttar Pradesh. Journal of Family Welfare (Special Issue), $56,57-64$.

Hossain-Sharif, M. I., Khan, M. E., Sebastian, M. P., \& Roychowdhury, S. (2008). Manul from Building Capacity of Trainers and Program Managers in Emergency Contraception. FRONTIERS. New Delhi, India: Population Council.

International Institute for Population Sciences (IIPS). (2010). District-Level Household and Facility Survey (DLHS 3) 2007-2008. Mumbai, India: IIPS. 
International Federation of Gynecology and Obstetrics (FIGO) and International Consortium for Emergency Contraception (ICEC). (2012). Mechanism of action: How do Levonorgestrel-only emergency contraceptive pills (LNG ECPs) prevent pregnancy? London and New York, NY: FIGO and ICEC.

Kishore, V., \& Misro, M. M. (2010). Providers' knowledge, attitudes, and dispensing practices of e-pills in government dispensaries of south district in Delhi, India. Indian Journal of Community Medicine, 35(1), 46-51.

Kumar, S., Shekhar, C., Gupta, N. K., Roy, M., Khan, M. E., Sebastian, M. P., Idnani, R., Bhargava, A., \& Salvi, V. (2007). Provision of emergency contraceptive services through paraprofessionals in India. FRONTIERS Final Report. Washington, DC: Population Council.

Lawrence, R. E., Rasinki, K. A., Yoon, J. D., \& Curlin, F. A. (2010). Obstetriciangynecologist physicians' beliefs about emergency contraception: A national survey. Contraception, 82(4), 324-330.

Ministry of Health and Family Welfare (MoHFW). (2008). Guidelines for administration of emergency contraceptive pills by healthcareproviders. New Delhi, India: MoHFW.

Nigam, A., Maheshwari, N., \& Prakash, A. (2010). Knowledge of emergency contraception and contraceptive practices: Representative study from rural Uttar Pradesh. Indian Journal of Community Medicine, 35(3), 449-450.

Puri, S., Bhatia, V., Swami, H. M., Singh, A., Sehgal A., \& Kaur, A. P. (2007) Awareness of emergency contraception among female college students in Chandigarh, India. Indian Journal of Medical Science, 61, 338-346.

Rubin, S. E., Grumet, A., \& Prine, L. (2006). Hospital religious affiliation and emergency contraceptive prescribing practices. Research and Practice, 96(98), 1398-1401.

Sychareun, V., Phongsavan, K., Hansana, V., \& Phengsavanh, A. (2010). Policymaker and provider knowledge and attitudes regarding the provision of emergency contraceptive pills within lao PDR. BMC Health Services Research, 10, 212. 
Tripathi, R., Rathore, A. M., \& Sachdeva, J. (2003). Emergency contraception: Knowledge, attitude, and practices among health care providers in north India. Journal of Obstetrics and Gynaecology Research, 29(3), 142-146.

World Health Organization (WHO). (2005). Emergency Contraception. Fact Sheet 244. Retrieved from http://www.who.int/mediacentre/factsheets/fs244/en

World Health Organization Department of Reproductive Health and Research (WHO/RHR). (2009). Medical eligibility criteria for contraceptive use (4th ed.). Geneva:WHO.

World Health Organization Department of Reproductive Health and Research (WHO/RHR) and Johns Hopkins Bloomberg School of Public Health/ Center for Communication Programs (JHU/CCP). (2011). INFO Project. Baltimore, Maryland, CCP and Geneva: WHO.

Yam, E. A., Gordon-Strachan, G., McIntyre, G., Fletcher, H., Garcia, S. G., Becker, D., \& Ezcurra, E. (2007). Jamaican and Barbadian healthcare providers' knowledge, attitudes and practices regarding emergency contraceptive pills. International Family Planning Perspectives, 33(4), 160-167. 


\section{Appendix}

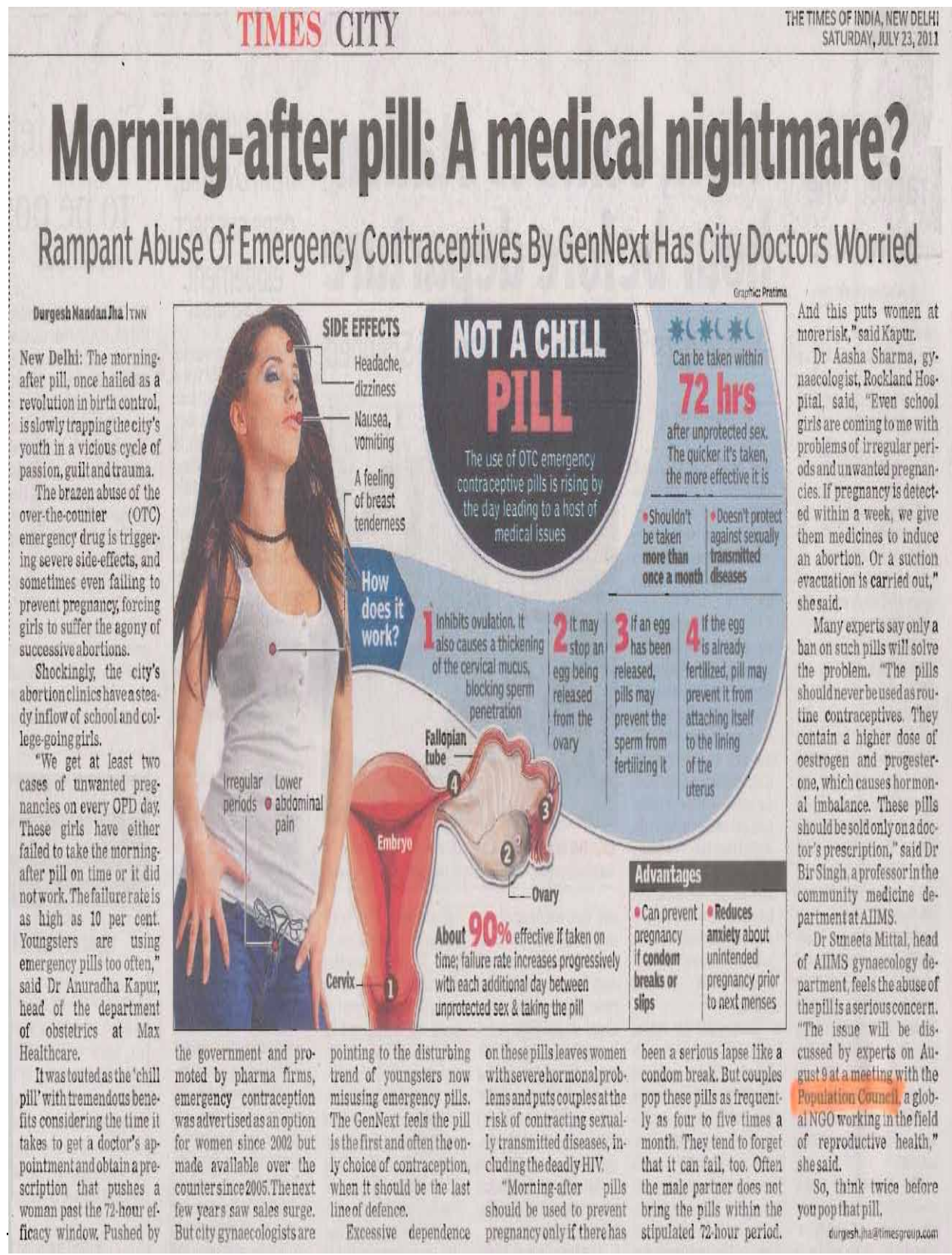


This report provides an analysis of the study on the knowledge, attitudes, and practices regarding the emergency contraception pill (ECP) among providers in public and private healthcare facilities and pharmacies.

The ECP is a unique method of contraception because it can be used post coital. However, its use has remained limited to urban areas, with very little penetration in rural areas. Considering the high rate of unwanted pregnancy in India, the ECP was introduced in the National Family Planning Program in 2002 and made Over the Counter in 2005. There have been newspaper statements by medical fraternity opposing ECP use on various grounds including side effects and its social impact such as promiscuity. A quantitative survey of pharmacists, doctors and paramedics was conducted in four cities of Uttar Pradesh and Delhi, qualitative in depth interviews of experts including gynecologists, senior government employees, officers of development organizations and an ECP manufacturing firm executive were also conducted to complement the findings. The study was carried out with technical and financial support from the International Consortium of Emergency Contraception.

The survey revealed that ECP is mainly being provided to a young section of women, by pharmacists who are not trained on ECP. Although providers believe that ECP is safe and effective, they lack correct knowledge on the mechanism of ECP and are often not in favor of easy availability of ECP to young and unmarried women. Higher availability of ECP was linked to issues such as repeated use and increase in premarital sex. The findings identify a need for educational campaigns, careful advertising, guidelines on repeat use, advocacy to tackle negative provider attitudes and IEC material which would have a direct bearing on policy, program implementation to address barriers to ECP access and to improve service delivery.

\section{(2) Population Council}

www.popcouncil.org

Zone 5A, Ground Floor, India Habitat Center, Lodi Road, New Delhi 110003

Tel: 91-11- 2464 2901/2, Fax: 91-11- 24642903

Email: info.india@popcouncil.org 